\title{
THERMAL MEASUREMENTS
}

\section{ON THE JUBILEE OF THE SIBERIAN RESEARCH INSTITUTE OF METROLOGY}

August 31, 2009 was the 65th anniversary of the setting up of the Federal State Unitary Enterprise Siberian State Order of the Red Banner of Labor Research Institute of Metrology (FGUP SNIIM) to meet the need to solve metrological problems of the rapidly developing industry, transport, academic and other branches of science in Siberia.

At the present time, the SNIIM is a research institute of a polytechnical nature with a developed infrastructure, which enables theoretical and experimental research to be carried out, and also to develop, manufacture and test new measuring instruments and data-measuring systems, for checking and calibrating a wide range of measuring instruments, and to develop and certify measurement procedures. The structure of the institute includes scientific departments and laboratories and a design bureau with test-experimental sections and other services.

Since 1994, the institute has been performing the functions of the State Scientific Metrological Center. The institute has available seven State Standards, seven higher-accuracy facilities, ten standard-copies, standard-certificates, comparison standards, and twenty-nine secondary standards. This enables fundamental and applied research to be carried out on ensuring unity of measurements in such areas as the measurement of the parameters of electric circuits at high frequencies and radio circuits at microwave frequencies, the electromagnetic characteristics of materials at high frequencies and microwave frequencies, the parameters of laser emission spectra, large masses and short lengths, weak magnetic fields, heat-exchange parameters, time and frequency, and the parameters of the rotation of the Earth.

The institute is one of seven Russian metrological institutes, whose participants, in 1999, signed the Paris Agreement "On the mutual recognition of national standards and certificates of measurements and calibrations, published by national metrological institutes." A considerable part of the institute's work is carried out in the framework of federal and interstate programs. Thus, standard samples of dielectric properties of materials at microwave frequencies have been manufactured in accordance with the interstate program for producing and using interstate standard samples of the composition and properties of substances and materials, and standard systems for the metrological backup of measurements of quantity of heat and heat carriers have been developed. At the present time, work is being carried out to set up a regional center to provide metrological facilities for nanotechnology and estimate the conformity of the production of the nanoindustry in the Siberian Federal district.

Considerable successes have been achieved in the department of the State time and frequency service and in determining the parameters of the Earth's rotation. Joint operations to test and improve the most advanced and promising Russian GPS-GLONASS receivers for precision coordinate-time measurements are being continued.

All these areas of research are supported by creative contact with Russian and foreign scientific organizations, which will also be developed in the future.

Beginning with this number of the journal, the editorial board plans to publish papers by leading specialists at the Siberian Institute, which reflect the areas of research being carried out there. In this issue, we publish papers devoted mainly to work being done in the field of thermal measurements.

Translated from Izmeritel'naya Tekhnika, No. 10, p. 48, October, 2009. 